\title{
Psychological problems in China in the era of transformation
}

\author{
Arnulf Kolstad ${ }^{*}$, Nini Gjesvik ${ }^{2}$ \\ ${ }^{1}$ Department of Psychology, Norwegian University of Science and Technology, Trondheim, Norway \\ ${ }^{2}$ Department of Social Work and Health, Norwegian University of Science and Technology, Trondheim, Norway \\ Email: ${ }^{*}$ arnulf.kolstad@svt.ntnu.no
}

Received 31 January 2012; revised 29 February 2012; accepted 16 March 2012

\begin{abstract}
The purpose of this study is to reach a better understanding of how minor psychological problems (MPP) are perceived in China by well-educated Chinese. An exploratory qualitative design is used. The results are based on interviews with professionals and students practicing Chinese medicine (TCM) and lay people from three urban sites. Minor psychological problems have traditionally not been labelled as disorders or illnesses but challenges in daily living or as "heart problems" and seemed to have less serious consequences than we are accustomed to think from a modern western outlook. "Problems of life" rather than sickness was the category that best summarized perceptions of such problems among the Chinese. It points to a salutogenetic perspective reflecting perception of mental health and MPP as processes of adaption and interpretation of meaning rather than medical conditions or sickness. Due to the influence from the West these problems are, however, more often comprehended as a health problems or even sickness, and not solely natural problems of life.
\end{abstract}

Keywords: Psychological Problems; China; Societal Change; Competing Values; Stress; Problems of Life

\section{INTRODUCTION}

Contemporary China is a society in fast transition, and many people express the view that the rapid changes and "modernization" create more mental health problems or at least more awareness of these problems. Especially in urban areas and among the educated Chinese there is an emerging acceptance of the benefits of psychological counselling. The understanding of minor psychological problems (MPP) has been influenced and conceptualized more in accordance with the Western viewpoints and diagnostic labels. But still traditional Chinese values and

\footnotetext{
*Corresponding author.
}

habits exert great influence on the comprehension of psychological problems. The lack of public and lowpriced mental health services also contributes to the disregard of MPP as something in need of treatment by health professionals.

This study focuses on how perceptions of minor psychological problems are understood and dealt with in contemporary China, a society characterised by change. There is a dramatic transformation from thousands of year of Eastern traditions to a Western affected society. This article describes and discusses how the Chinese deal with these changes when it comes to the perception and handling of MPP. Many Chinese attribute an increased prevalence of MPP to the contemporary cultural tensions and the more "modern" way of life. They emphasize economic burdens and pressure perceived by individuals, conflicting values, and generation gap problems due to societal transitions and MPP are perceived as adjustment problems. Values in conflict, the tension between the old and the new China is looked upon as important causes of MPP. The traditional interdependence and harmonious relationships is not the only given purpose of life any more. Personal achievement and independence has become competing aims. In the tension between competing goals the minor psychological problems seems to be more prevalent than in the stable traditional Chinese culture. And they are more often comprehended as a health problems or even sickness, and not solely natural problems of life. For several reasons such problems are however still neglected by most Chinese. May be with good reasons.

The rise of MPP in the young generation is nevertheless a concern in China. Many studies explain the change of values towards an individualistic perception of self as a result of the one-child policy, "modern" child rearing emphasising individuality, the reform policy, market orientation, and pragmatism [1-4]. The family institution, the basic core in traditional China, is under attack and slowly transforming its function. The young generations are influenced the most by the transformation of the tra- 
ditional Chinese culture.

\subsection{Divorce Rates Increasing}

Relationships are changing and families split up due to the dismantling of traditional Chinese values and norms. The rate of divorce increased by 18 percent from 2006 to 2007, and the number of divorces in China in 2007 was 1.4 million. There are many explanations for this rise: heavy work pressure and infidelity, that many women do not accept infidelity and that people have higher expectations of one another. This reflects that dependent relationships and attitudes associated to traditional role functions and hierarchy are in change.

\subsection{The One-Child Policy}

The consequences of the one-child policy have created a big supportive responsibility for the single child and changed traditional family relationships. The general opinion of the spoiled singleton syndrome is, however, misleading since it does not specify by whose standard and in what ways the singletons are spoiled [2]. The causes of the psychological problems are rooted in the demands for success in the "new" society and not solely related to the one-child politics. In a nationwide survey in 2005 by the Research Centre of Chinese Youth 57 percent categorized their lives as unhappy, and in another survey among teenagers in Shanghai in 2001, 61 percent perceived not having enough sleep and 21 percent of the youth always felt exhausted [2]. The conclusion was that the majority of China's youth find themselves constantly under pressure and that they are anxious. Worries, fears and anxiety about their future, along with the daily calculated efforts to move oneself ahead, take a serious toll of China's youth [2], and the high pressure on performance and competition may induce apathy and aversion among the young emperors and empresses who have been supplied abundantly and are regarded as spoiled [5].

To achieve good grades is related to being a good child, a successful child. Students entering the best colleges and universities are the highest scoring students in their districts, and they have to adjust to getting lower grades without losing their self-identity. Their sense of self and self-esteem is founded on the role of being a good child and performing well at school $[6,7]$. The important function of grade is reflected when 42 percent of the students in the nationwide survey of 2005 considered having good test-scores the happiest thing in their lives [2].

\subsection{Changing Values in China}

The traditional Chinese collectivism or interdependence promote a more social or interdependent self-appraisal than in individualistic cultures. How you are regarded by others is very important to how you regard yourself. Values connected to individual achievement and reflected in individualism have become important in China $[1,2,5]$. They are, however, still connected strongly to collectivistic motivated goals like a better future for the whole family and even for the "motherland": China.

Some studies promote the view that value systems are "physical realities" and "subjective interpretations of society by different social layers"; they are "accepted in different shades of intensity among definite segments of society" [8]. Although one can discern a dominant set of values of a society, supported and espoused by those in power, there is always an undercurrent of protest and a different, deviating, and competing set of values, which can be conceptualized as conflicting values [8]. During periods of transition conflicting values often become more prevalent and explicit and they are accepted to different degrees by different social layers. In China the conflicting or new values characterise first and foremost the young, educated generation in urban settings. Values that were perceived as conflicting by individuals in this study seemed associated with perceived subjective tensions related to MPP.

\subsection{Pragmatism}

Some researcher's hypothesis that China is in the throes of a cultural transition where traditional values are declining partly as a result of social and economic transformations and partly due to the adverse impact of the Cultural Revolution [9]. This hypothesis is supported by recent anthropological studies on values in China $[1,2$, 10]. There is transition of values from traditional Confucian values of filial piety, obedience, respect, benevolence, and self-restraint on behalf of personal interest, money, and personal prosperity and success. The younger generation is recognized to be pragmatic [9], which is regarded as a clear evidence of their rejection of traditionalism. Pragmatism may lead to utilitarianism and materialism with a focus on individual possibilities and needs to be above the concern of others.

The concept anomie has been related to increased rates of suicide and linked to loss of subjective meaning in a society where norms and values are changing or in a vacuum [11]. This is a result of multiple and rapid transitions, changing values and norms, and lessening social ties. It promotes a subjective sense of loss of meaning and the feeling of being socially obligated, including knowing how to act and what is right/normal/good and what is wrong/abnormal/bad. Anomie and atomie have also been related to transitions in modern societies, where atomie is defined as the feeling of being left alone, the loss of common values, social obligations, sense of belonging, and the feeling of being valueless [12]. 
Pragmatism in a broader sense is not a new phenomenon in China but closely related to thinking and perceiving change as part of life. A practical reason related to "this worldliness" is a characteristic of Chinese thinking and culture [13]. Chinese mode of thought centers on practical affairs and a cognitive mode based on intuition, characterized by a vague grasp of the totality, the absence of rigid logical reasoning, and abstract theorization $[13,14]$. Chinese medical concepts generally reflect the central theme of Chinese culture characterized by a dialectic interaction between the ideas of Tao and a strong material pragmatic orientation [15]. Change and pragmatism reflect Taoism and are embedded in Chinese traditional philosophy and Traditional Chinese Medicine (TCM). Taoism is reflected in TCM concept of health and sickness as the balance of dynamic processes of inside and outside relationships.

Pragmatism may be regarded as an attitude of acceptance and adjustment to changes and maintaining harmonious relationships, which is a part of traditional Chinese culture reflecting the interdependence of man and nature. A Confucian saying expresses the importance of a pragmatic attitude, which may be expressed as going with the changes, the way of Tao: "Do not dwell in the past. Do not stay in the present. Change with the trends. Change with the time”. The $16^{\text {th }}$ Party Congress of 2002 expresses this pragmatic attitude in the saying: "Keep pace with the times and create something new!" Change as knowledge of how life goes reflects an ontological position of traditional and contemporary culture. The history of China in the last century has been filled with changes. This may have emphasized the importance of a pragmatic attitude and "lean to where the wind blows". A knowledge of the world as changing influences how life events are perceived. It may reduce the subjective sense of anomie in a society of transition with changing norms and values.

Some researchers point to the important role new media play in promoting globalization and changing attitudes [16]. A study of the women's movement in China and a study of telephone counselling in China both emphasize the effect of internet, the use of hotlines, and web online counselling in transmitting changes of attitudes toward MPP [3,17]. This reflects a change of knowledge and attitudes influencing perception of MPP as problems in need of attention and professional help. Only a minority in China would consider professional help for minor psychological problems, and the information from the new media do not reach the majority of the population

Most Chinese can hardly afford psychological treatment for MPP and they would not give priority to it. There is a lack of knowledge of MPP from a perspective of sickness as well as professionally trained psychologists and counsellors.
Knowledge and attitudes toward mental problems as sickness associated with professional treatment or counselling seem, however, to be changing rapidly with the increased importance and use of media. MPP may from this perspective reflects culture as process and how cultural knowledge is negotiated, reflecting contemporary Chinese societal processes and globalization of knowledge [18]. Younger participants had a better understanding of mental illness and had a more accepting attitude to MPP than the older generation [19]. This is attributed to national trends of public efforts in reducing stigma by new labels, increased awareness and educational programs.

\section{METHODS AND MATERIALS}

The aim of the study is to see how the transformation of the Chinese society influences people's perception and attitudes regarding minor psychological problems. A fieldwork design was chosen. It makes it possible to be at the place, participate, and observe. Living in Chinese neighbourhoods and eating at local restaurants provided observational and contextual data for interpreting meaning of daily life in urban China. Watching television and reading Chinese newspapers and being aware of news about health issues were sources of knowledge and information. Visiting temples, joining exercises in streets and parks, travelling on trains and buses, and making study visits to rural villages contributed to impressions of links between traditions and contemporary daily life practices. Informal talks with people, telling about the study, also provided a basis for interpretation and meaning making. One of the authors has lived in China for eight years.

\subsection{The Interviews}

Interview data were collected in China from the fall 2006. By interviewing Chinese, listen to their attitudes, perceptions and stories, and by using a dialogical approach, a further insight into how they perceived the transformations going on and especially psychological problems were acquired. The Interview data provide a base for developing meaning and categories to approach participants' perspectives and the dialogue represents a hermeneutical process of understanding.

Questions related to traditional Chinese culture/medicine were based on Chinese concepts. The intention was to use emic concepts to get close access to the meaning the Chinese themselves put into it and avoid the use of Western diagnostic etic concepts, which might reflect a colonized Western perspective of mental ill-health.

\subsection{Sampling}

Purposive sampling was chosen for many reasons. Inclu- 
sion criteria as being Chinese and living in China were obvious to elicit a Chinese meaning within a Chinese contemporary context. Different regions of China may represent different stereotypes with regard to the importance of traditional culture and modernity. Three different sites were chosen for fieldwork and interviews to get a mix of attitudes in case these stereotypes were of importance. The difficulties of getting access for foreign researchers in China, the challenges, and frustrations underscore the necessity of being flexible in the process of sampling [20]. The selection of participants went on during the field stay and represented as such "casual" or "opportunistic" sampling [21].

Three TCM doctors and 3 TCM students were interviewed. They were placed in three different geographical contexts in China, a city in the west, a city in the north, and a city in the east. The doctors had been working abroad for a period of time, which influenced their knowledge of MPP. Two of the doctors were professors. They were interviewed in their work context. Five of the 8 participants outside a TCM context were recruited through an advertisement in an internal university webpage connected to psychological counselling service, by requesting volunteers for interviews about mental health. This may have selected participants with a specific interest and knowledge in psychological issues and mental health. The 14 people interviewed (age: 22 - 40, sex: 6 males, 8 females) are all non-patients. Translation seemed to complicate the access of shared perspectives and an inclusion criterion was therefore mastery of conversation in English but not requiring fluent language.

The sample consisted of urban people with an academic background. Although many had grown up in rural areas in a traditional Chinese way, their education level was high and urban experiences had influenced their attitudes and knowledge. People within a rural context, with less education or older people, the scientific knowledge would have been less influential and the traditional knowledge might have been stated even more clearly.

\subsection{Ethical Reflections}

The participants were informed before the interview of the aim of the study, about anonymity and the possibility of contact afterwards. Every one interviewed gave an oral consent to the interview. To protect the anonymity, no names were noted. Everybody except one of the participants had any objection for tape-recording the interview.

\section{RESULTS AND DISCUSSION}

\subsection{Changing Knowledge and Attitudes}

The well-educated participants in this study express that knowledge and attitudes towards MPP are changing. When talking about how they perceive MPP, many refer to the educational programs and an increasing influence of Western culture.

Q: Do you think minor mental problems are understood differently in China than in the West?

Now it seems all westernized. In the past we didn't have mental hospitals. It all comes from western countries; psychological therapy and hospitals. Nowadays more and more people go to the psychological consultant. It has just started the last 3 or 4 years. Before that we didn't know what to do, maybe we found friends to talk with. Some students go to the consultant, and more and more people don't feel ashamed of going to the consultant nowadays. And just go to the consultant is a big progress since some people kill themselves, especially in the famous universities. They don't even go to the consultant. (Student).

Q: Because they are ashamed you think?

Ashamed and they don't believe in it, that it will help them. They just say, I have my own problems and I will solve my own problems. (Student).

The student refers to a change of attitude towards psychological problems and an increasing use of psychological service for MPP, which she regards a result of increasing influence of the Western concept of mental health. Stigma, shame and a sense of strangeness seem to keep people from using these services. It reflects a lack of trust in the alleviation of problems by talking to professionals. This aligns with a general attitude connected to underuse of mental health services among Chinese overseas and in Hong Kong. They have better access to these health services and there is a less stigmatized attitude in society in general [19,22-24].

One of the participants represents an exception in his perception of MPP, which complies with a Western perspective of sickness. He says that most people lack the knowledge that makes them categorize mental problems as mental disorders or sickness and they lack even the vocabulary and language to express problems this way. This will of course influence the way they deal with and resolve such problems. Problems not perceived as sickness are handled outside the health services and without professional counsellors. To perceive MPP in the Western way as sickness or a mental disorder is not the common way in China, even among the urban, educated population. There is however a change in this direction and some of the students interviewed represent the Western way of comprehending such problems.

Those who look at MPP in the Western way, as sickness, still cannot share this new way of perceiving problems with friends or family. When one of the students tried to explain his perspective of MPP as a mental disorder to friends, they found it unbelievable and strange. 
This reflects two different ways of "knowledge of the world" or perspectives on psychological problems prevailing in contemporary urban China.

The student says he has joined a club for people with social phobia with whom he can share his perspective of MPP within a Western concept of social phobia as sickness. Internet also seems to play an important function in providing knowledge of MPP in a Western perspective. The Web links people who experience MPP to share their perceptions of these problems from a perspective of sickness without being stigmatized.

\subsection{Changing Relationships, Values and Stress}

The TCM doctors and students do not differ from the lay perspective in how MPP are attributed to the rapid changes in society, the new goals, and improved economic conditions. The TCM professor in East city emphasises the psychosocial stress connected to societal changes.

We call middle class people working in offices "white collar persons", and it is very common among this kind of persons to have the stress. Even doctors are stressed when you are always busy. One reason for stress is the job, another is the family. Some people have changes in their position and with the heavy pressure in their life and in their job. They have no time to take care of the family. Another reason is everybody coming to the big cities, the market increased a lot and then you need people working. And you are looking for this, you get a wonderful job but you have the pressure. The divorce rate also increases a lot and makes heavy burden on the families. Many people in the family lose their parents. (TCM professor).

The professor links MPP to perceived stress, a result of competition and strain to promote goals linked to a modern and more competitive and independent society. He emphasizes how strains on relationships and the rapid changes have made families smaller and more vulnerable, influencing peoples' family life, social network, and social safety.

A study measuring the effect of market reform and psychological distress among Beijing residents in 1991 and in 2000; supports the doctor's understandings of psychosocial stress as important in creating MPP [25]. The increase in psychological distress they found in 2000 was mostly due to greater exposure to life stressors. The results showed that relationships have a protective function and that the effect of social relationships and family life has gained importance as precaution measures towards stressors and MPP.

\subsection{Thin Relationships}

The Chinese, especially in the urban areas, talk more about psychology, stress and MPP than ten years ago when these concepts hardly existed in the Chinese language. To deal with such problems by seeking professional help has become more common and better accepted especially in the urban areas.

Psychological counselling and treatment are not very common in China since we traditionally share problems and worries with family or friends. They do the job of a psychologist. In Western countries people always want privacy. So when you feel you are not lonely you will not get mental diseases very easily. And now I think psychology problems in China becomes more and more popular because the traditional thinking and relationships become thin. Just on their way to disappear.

You know in our ancient time, the human sympathy and human feelings were richer than now. The relationships are harder now, and the family responsibility was more before than now. (TCM students).

Q: So before you had more feeling and sympathy, it was richer before, but are becoming thinner you say?

Yes and you can say there are more mental diseases in China now, and psychologists can be found in some Western medical hospitals now. But 30 years ago they could not be found (TCM students).

This student focuses on the close relations between societal changes, values, and psychological problems. She describes the increase in mental problems and disorders as a result of more loneliness - a feeling of being independent or separate. She describes that China changes towards individualism and that traditional values and relationships fade out. A harder society grows up with less concern for each other-less focus on the Confucian principle of benevolence. Change toward individualism make according to this student MPP more common and psychology more accepted.

This reflects how societal changes influence how people think, feel, act, and relate to each other. Changes in attitudes and values toward individualism are prevalent in both urban and rural China [2]. The exchange of knowledge and values is aided by modern media like TV, Internet, and cell phones and the migrant labour force moving between urban and rural areas [2].

The concepts of anomie and atomie describe how societal changes and modernization processes influence norms and values, sense of meaning, and mental health $[12,26]$. The changing values and movement values directed toward individualism may induce a sense of being separated from others and a sense of meaninglessness. Change is reflected in more emphasis on values connected to individualism not considering the other, reflected in a pragmatic attitude of utilitarianism.

\subsection{Too Much Love May Bend the Heart}

Some respondents mention how the population policy 
(one child family) has influenced the social order of the family system in terms of less obedience and respect for the elders, which may cause tensions and conflicts.

$\mathrm{He}$ : The children are the essence of the family. We have a joke saying: In this family, the mother will obey the husband, the husband will obey the grandfather and the grandfather will obey the grandson or granddaughter. This is a circle. The grandson is the boss of the family. This is a kind of joke but it tells a real phenomenon in traditional China.

She: The Chinese children have the adverse reaction against their parents, this phenomena is becoming more prevalent.

$\mathrm{He}$ : In ancient times the parents produced lots of children so they didn't have enough energy to teach and control each child well. Now, with the law allowing only one child, two parents and four seniors take care of this one child. All these six people are taking care of one child! He/She would have to listen to the same word six times. Too much love will bend the heart. I think too much love can damage the children. (TCM students).

Q: You think that makes problems or adverse reactions?

He: Few, some of them will have this problem, but most of them are the common people. When the child grows up, the adult people will let him go, leave him alone. But some of the children if they didn't have a strong mind or the heart, and bear the damage of the love, they are too fragile, maybe the mind will be developed towards the wrong way and maybe some of them will suffer from psychological problems. (TCM student).

These two TMC students underline the importance of leaving the child free to become independent as a constant challenge that parents face. They attribute MPP to spoiled children bearing the damage of love. To be spoiled may cause a fragile mind, and they refer to the importance of having a strong heart-mind. Referring to adverse reactions, they emphasize the transition between being dependent and becoming independent and refer to the situation of the singleton with concern, love, and attention from parents and grandparents and how this may influence the process of becoming independent. What the TCM students say is in accordance with what has been revealed in China by other studies [1-5], that the demands for independent success in the "new" Chinese society in combination with the one-child policy is an exigent blend, and lead to a rise of MPP among the younger generation.

The standards and dreams of parents together with the perceived social obligations to the family point to how many Chinese youngsters feel caught in a pressure to perform according to certain goals. This may create conflicts in relationships, emotional distress and symptoms of MPP. Together with the reform politics, the population policy has resulted in a focus on the single child and its abilities to perform in a sense of individualism. It has also changed the relationships in the families towards a horizontal individualism that did not exist in traditional China.

\subsection{Suffering and Independence}

Many respondents claim that suicides and MPP are more frequent in the highly ranked universities. A student interviewed underlines the higher demands for success and the necessity of becoming independent as contributing factors, and she relates the problems partly to be a consequence of the spoiled, or at least overprotected beloved only child.

Chinese parents love their children, and the way they love create some problems. I was like a princess. I did only know how to wash myself, not my clothes or do some of the basics things in life. I was not independent. I was just very dependent on my parents. My parents got me in their 30's and they loved me very much and did everything for me. So I just studied and made the high scores in school and they would say my daughter is very good. But when entering the university you don't get the best grades, and your parents are not beside you, most are far away and you think nobody love me. And first year in university I did not know how to wash my clothes, thinking oh I want my mo. So I think the one year I graduated from university I just learned, and now I am learning how to become independent. I think it is very hard for many, many Chinese children, especially the university students graduating from the good universities, because the Chinese education, their children, they treat them and their parents didn't want them to meet any difficulties. But to become independent person, you have to suffer something very bad, or something very important, you can't escape from this. I think if you didn't suffer anything you do not become independent. You must suffer from something; then you can learn. Learn who I really am, what I'm good at, then you can do the right thing to hunt the right goal, use the right way. (Student).

Like this student, many of her co-students are brought up as dependent in a protected position as the only and beloved child, called emperors or princesses. When they start to study at the university they have to adjust to a more independent life style. This represents a strain and challenge to sense of self and self-respect.

The student says that to endure suffering is a part of becoming independent, a necessity on the way to reach goals. Suffering and worries does not seem to be categorized as symptoms of MPP but may probably have a reference to how suffering is reflected in Buddhism, a philosophy which has greatly influenced Chinese for centuries. It is expected that Buddhism also have an impact on 
how Chinese think and interpret such problems, as this student says:

Buddhism affects Chinese people's thinking. In Buddhism suffering is the universal experience. Like maybe another day it will be better; one day good, one day bad. (Student).

Suffering therefore seems to be embedded in what people regard as a normal and necessary aspect of life. The dialectical relationship between happy and sad, ups and downs, suffering and growth is part of a cultural knowledge where different philosophies and religions (Confucianism, Taoism, Buddhism) have merged in a perspective of culture as knowledge of life. This knowledge is embedded in the values and in what is regarded as virtues. It also underlines that perceptions of MPP are related to morality [27]. Diligence and endurance are highly regarded values, and many have been trained through their childhood and education that endurance and even suffering is necessary for success. Endurance and suffering reflected in symptoms of MPP is the price of being independent and a successful student.

\subsection{Meaning and Goals}

Some participants claim that conflicting values and goals of parents and their children may cause problems with identity and meaning. Others say that expectations to perform or enter college are goals that prevent MPP. This reflects the importance they place on goals for meaning and how they relate loss of meaning to MPP.

Q: When you say that you think many Chinese have psychological problems, what kind of problems do you think it would be?

Boring, nothing to do. Sometimes if they could not find a good way to solve them or get good results you put in the deep of your heart. I always felt like a hole in my heart where I could put everything inside, just like in the universe it is a big hole. Life is just like this, nothing different, not colourful, just like this, repeat, repeat.

When I lived with my parents the problems were just between them and me. To study far away from home was a good thing for being independent; I can do what I want. If I was at home they would decide more not allowing me to do this and that. And I can disagree with them. And sometime I lie to them even if I don't like lying, that is not a good thing. They would like me to marry in my hometown and maybe someone they know, and if he was not good to me they could help me. But in my generation we think totally different, maybe we don't want to live together. In Chinese tradition divorce is unthinkable, even if you don't love each other you should live together. But for young people it is different.

To get a good job, to have a goal makes you study hard. Different people have different goals. Many stu- dents have the goal of becoming a CEO (chief executive officer) knowing you then will have a very good future. To many a good life is a big house, a wonderful car. These are things we can see and touch. For other people different goals; in their heart they research to find things other people didn't find, not the material kind. (Student).

The student tells of a period in her life filled with meaninglessness. She links MPP and the sense of meaningless to lack of goals. She does not want to be dependent on her parents' values and goals and searches her own independent goals. This makes strains on the relationships with her parents, but accepting their goals made her feel that her life was boring and meaningless. She relates MPP to conflicting values and existential problems of meaning. Her goals are to be independent and to find her own way, even if this causes conflicts with her parents.

She seems oriented towards new norms and values, which reflects individualism. An ethnographical study on family changes of moral experiences in a Chinese village from 1949-1999 emphasizes how societal changes have led to a decline of parental power, authority, and prestige accompanied by a rise of youth autonomy and independence [1]. The previous logic of intergenerational reciprocity needs to be redefined with the rise of the nuclear and private family and the lives of the individuals within the family. Emotionality, desires, and personal freedom have become legitimate aspirations and part of everyday practice. Unlike the traditional family, the contemporary individual is concerned with the well-being of the nuclear family; father, mother and a child, at present [1]. This is very different from traditional family life and relationships in China. The new goals and values and how this gives meaning represent a change from interdependence, collectivism and harmonious relationships toward individualism with looser relational ties, a request of individual freedom, autonomy and more independent sense of self [28].

\subsection{Standards to Be Judged by}

Some relate MPP to a confused sense of self and the difficulties in handling changes and the conflicts between what is regarded as virtuous. What is considered as right and wrong is no longer as obvious as before, when the traditional Chinese culture and traditions where obvious and inevitable.

Q: When I say "minor psychological disorder" what would you think of, what kind of problems?

He: People don't know what they want, they do not know what they can get. And...

She: Feel depressed.

He: Depressed or feel bad about everything. Because they cannot recognize themselves; they don't know who I 
am.

She: I see, maybe his opinion is that people can't identify what he is, he is confused about some right or wrong things, just like: what should I be looking for or what man can I be just now. It is a thought problem I think, but it really troubles these people.

She: I think in China more and more people are concerned about this psychology science and we can find more meaning of life by thinking of these things which are not just material. People are concerned with their career and success but they pay little attention to the family relations or the friendship between each other. Our country is developing now, and more people pay attention to how much money you earn, and this is like a standard to judge a person. So the morality seems silent nowadays, it is really a problem, a new problem.

He: The education just tell us about the technology, not tell us how to be a man, a good man, how to live.

She: When we are in high school we are taught, the student who is a first class student, they have the most excellent test scores, but they didn't care how they made it, and whether they will help others, share with others students, the teacher did not care.

He: They only care about the goal.

She: I think people don't want to be a bad guy, they also want to be good. But our standard has directed us to earning. We are directed to think high salary is a good things, so we are so confused. (Students).

These students place MPP within a context of societal changes closely linked to values and changing norms. The standards to be judged by are both according to the old standards of the Confucian ethics and the new standards of individual prosperity and personal happiness. Recent studies emphasize the need to revise the scholarly conception of Chinese characterized by collectivism and to focus on the deep changes in Chinese society towards individualism [1-5,10].

The reform policy has provided opportunities for individuals to improve their personal economy, which many associate to a good future. This is the criterion of success according to the standards of contemporary Chinese, who look to the West as the first world [5]. The communist ideology connected to collectivism, which was earlier important in education and socialization of the correct thought, has changed to pragmatism reflecting utilitarianism connected to how to reach personal goals without too much morale concerns. The students point to how morality seems silent nowadays and connect this to a confused sense of self. This confusion also seems to represent a conflict between utilitarian goals and values and traditional virtues of benevolence and filial piety. The conflict between what is regarded as virtuous and to be a good child, a successful child, make tensions between generations, in society, and in the minds and emo- tions of individuals. These conflicts represent a threat to meaning in terms of morality, sense of self, and sense of coherence. It reflects a transition in society towards individualism, looser relational ties, and confusion in values. The confusion reflects a sense of anomie and atomie, a loss of meaning, a conflict in sense of self between independence and interdependence, and increase in MPP.

\subsection{Happiness Is Secondary}

Many respondents connect MPP to happiness and not being happy. Some relate this to their perception of psychology from the West and its focus on happiness. It is also linked to how traditional Chinese culture emphasis happiness, closely connected to the beauty of nature, and the enjoyment of a simple family life [29]. To most Chinese personal or private happiness is a secondary thing. If the abstract and psychological "happiness" is considered it is most often related to a prioritization of goals for a better future, safety and improved economic conditions.

He: In China some people don't care of how the mental could be. They care about the money, how life can be safe, the basics.

She: Maybe it is caused by the economic situation in our country that we are not very rich now and we, all people are still searching for some material dependence such as, house, clothes, food, so many things.

He: They don't know how to go into the mental question. If we get out of the poor condition then we should get the happiness. But we don't know of happiness. Our minds don't think about happiness. We don't know how to care about "happiness". Many people in China don't know to care of the second thing. They only care about the big things, and happiness is a second thing (Students).

Perception of MPP as "not important" is prevalent among most people we met in China. To regard happiness as secondary reflects a pragmatic attitude of accept and adjust to what is most important. The big issue is to improve their families material well-beings and in this way their safety. This is closely linked to societal and political changes after the reform policy where the individuals to a large extent are responsible for their own as well as their families' economic security. It is a part of felt obligations in a mutual dependency, a part of the expectations many have to live up to as a consequence of the one-child policy.

A study of the economic, social, and psychological consequences of China's one-child policy emphasizes the quest of many youngsters and their parents' expectations of becoming a part of "the elite" [5]. These expectations disclose how Chinese youth are caught in a web of interdependence where the societal and political measures 
have made the families smaller and more dependent on mutually shared obligations regarding economic security. These economic obligations influence perceptions of MPP in terms of prioritization of what is important and not, and what is regarded as serious and not serious. By including a societal perspective the respondents are revealing how they perceive MPP as reactions on societal changes and changing life conditions. Perceptions of MPP and how such problems are dealt with are closely connected to societal processes.

\subsection{Prioritization}

A TCM student was asked why he think mental problems appears:

MPP are more common today because of the modern way of life. People have to work much and many have problems with the economy. Not like before when people lived in the countryside and had more time. Today one has to be in a city to get a job and money and people have lots of worry about future. No governmental support and if one in the family gets sick it costs a lot. People in the countryside are very poor. (TCM student).

People in rural areas are still very poor and the people in the big cities with high costs of living have economic burdens and worries about the future. Most people are not fully covered by health insurance [30]. This lack of public financing of the health services highly limits the access for many people.

I think for most of the people they have the minor mental problems, but they just think I just need one or two days rest and I will recover, and they don't pay attention to this kind of problem. No money or no time.

Before the reform you did not need much money because you could get everything from the government, but now you have to buy everything and you will worry; I have to pay the kindergarten, education; primary school, high school, university, my doctor, insurance, and many also would like a car or an apartment or a townhouse. So people work very hard. They never find a good way to relax themselves. (Scholar).

These explanations attribute MPP to increased pressure on individuals related to societal changes after the reform policy. It emphasizes the individual responsibility to provide basic social services as education, medical services and housing as well as the pressure this has created on individuals.

Shifts in state health care policies during the post-Mao period, from guaranteed medical care to more complex combinations of reimbursement and self-payment, have meant that individuals have to pay health care costs out-of-the-pocket [31]. Medical and health care has been trapped in the tensions between growing social needs and constantly shrinking resources [32]. Changing politico- societal values shape knowledge and practice, judgment of seriousness, and help-seeking behaviour. This is reflected in how MPP are perceived. A greater demand on prioritization by the individual is necessary because the earlier health and welfare programs no longer exist for many Chinese, especially the poor ones on the countryside. This situation forces people to prioritize, illustrated by the young TCM doctor who mentions that the family can give priority only to the most serious illnesses. Parents having MPP will, due to the difficult economic situation, not seek a doctor unless they have serious health problems or life-threatening conditions.

To consider MPP as not important and not a serious problem reflects the everyday situation for many Chinese in a modern competitive society with little time or money for individuals to pay attention to minor problems of health and illness.

\subsection{Conclusions}

Changes in society highly interact with how life is lived, what creates tensions, and how these tensions are considered. Most people regard the fast changes in China and harsh economic conditions to be related to an increase in MPP. MPP are however, not considered as very serious problems and not given priority for treatment, partly a consequence of the health and welfare policy of contemporary Chinese society.

Relationships and values in transformation from traditional Chinese to Western values and ways of living create tensions, which may develop to MPP. Sense of self and personal goals is caught in dilemmas between interdependence and independence. Individualism is reflected in less dense relationships and less importance of vertical relationships. It actualizes Durkheim's theories of how anomie reflects a society in transition and a vacuum of norms.

\section{REFERENCES}

[1] Yan, Y. (2003) Private life under Socialism. Love, intimacy and family change in a Chinese village 1949-1999. Stanford University Press, Stanford.

[2] Yan, Y. (2006) Little emperors or frail pragmatists? China's 80ers generation. Current History, 105, 255-262.

[3] Gao, Y. (2001) Directive approach to telephone councelling in the People's Rebublic of China: Underlying cultural traditions and transitions. The Councelling Psychologist, 29, 435-453.

[4] Huang, J. (2000) Traditions and transformation. A research into the change of interpersonal relations in Dujia. University of Bergen, Bergen.

[5] Fong, V.L. (2004) Only hope. Coming of age under china's one-child policy. Stanford University Press, Stanford. 
[6] Rolandsen, U.M.H. (2004). In pursuit of education. Attitudes towards education in a rural Chinese township. Master's Thesis. University of Oslo, Oslo.

[7] Bakken, B. (1994) The exemplary society: Human improvement, social control and the dangers of modernity in China. Universitet i Oslo, Oslo. Institutt for Sosiologi, ISO-Rapport nr. 9.

[8] King, V.T. (2008) The sociology of Southeast Asia. Transformations in a developing region. Nias Press, Copenhagen.

[9] Chu, G.C. (1985) The emergence of the new Chinese culture. In: Tseng, W.-S. and Wu, D.Y.H., Eds., Chinese Culture and Mental Health, Academic Press, Orlando.

[10] Liao, B.P. (2000) From the "god and ghost" world to the "human and nature" world: Study of the changes of health care in Yongxing Village in China. University of Oslo, Oslo.

[11] Durkheim, E. (1897/1991) Selvmordet: En sosiologisk undersøkelse. Gyldendal, Oslo.

[12] Galtung, J. (1995) On the social costs of modernization. Social disintegration atomie/anomie and social development. Discussion Paper 61 (DP61). UN Research Institute for Social Development, Geneve.

[13] He, P. (2002) China's search for modernity. Cultural discourses in the late $20^{\text {th }}$ century. Palgrave Macmillan, Oxford.

[14] Nisbett, R.E. (2005) The geography of thought. How Asians and Westerners think differently and why. Nicholas Brealey Publishing, London, Boston.

[15] Lin, K.-M. (1981) Traditional Chinese medical beliefs and their relevance for mental illness and psychiatry. In: Kleinman, A. and Lin, T.-Y., Eds., Normal and Abnormal Behavior in Chinese Culture, D. Reidel Publishing Company, Dordrecht, 95-111.

[16] Lindhoff, H. and Rydholm, L. (2007) Media cultures and globalization in China. Stockholm Media Studies: 1, Proceedings Form a Cross-Disciplinary Conference in Stockholm 2004, Stockholm.

[17] Milwertz, C. (2002) Organizing for change. A new wave of Chinese women's movement. NIAS Report Series, No. 40, NIAS Press, København.

[18] Thorsen, K. and Toverud, R. (2002) Kulturpsykologi. Bevegelser i et livsløp. Uniforlaget, Oslo.
[19] Hampton N.Z., Yeung, T. and Nguyen, C.H. (2007) Perceptions of mental illness and rehabilitation service in Chinese and Vietnamese Americans. Journal of Applied Rehabilitation Counseling, 38, 14-48.

[20] Heimer, M. and Thøgersen, S. (2006) Doing fieldwork in China. NIAS Press, Copenhagen.

[21] Patton, M.Q. (1990) Purposeful sampling I: Qualitative evaluation and research methods. Sage, London, 169-186.

[22] Tseng, W.-S. and Wu, D.Y.H. (1985) Chinese culture and mental health. Academic Press, Orlando.

[23] Yip, K.-S. (2005) Chinese concepts of mental health: Cultural implications for social work practice. International Social Work, 48, 391. doi:10.1177/0020872805053462

[24] Kim, B.S.K. and Omizo, M.M. (2003) Asian cultural values, attitudes toward seeking professional help, and willingness to see a councelor. The Counseling Psychologist, 31, 343-361. doi:10.1177/0011000003031003008

[25] Lai, G. and Lee, R.P.L. (2006) Market reforms and psychological distress in urban Beijing. International Sociology, 21, 551-579. doi:10.1177/0268580906065301

[26] Lian, O.D. (2003) Når helse blir en vare. Høyskole Forlaget, Kristiansand.

[27] Helman, C.G. (2007) Culture, health and illness. 5th Edition, Hodder Arnold, London.

[28] Armstrong, T.L. and Swartzman, L.C. (2001) Crosscultural differences in illness models and expectations for the health-care provider-client/patient interaction. Handbook of Cultural Health Psychology, Academic Press, London, San Diego, 63-84.

[29] Lin, Y. (1998) My country and my people. Foreign Language and Research Press, Beijing.

[30] Wong, C.-K., Lo, V.L. and Tang, K-L. (2006) China’s urban health care reform. From state protection to individual responsibility. Lexington Books, Lanham.

[31] Chen, N.N. (2001) Health wealth and the good life. In: Chen, N.N., Clark, C.D., Gottshang, S.Z. and Jeffery, L. Eds., China Urban Ethnographies of Contemporary Culture, Duke University Press, Durham, London, 165-182.

[32] Yang, T. (2006) Introduction: Reform of the public health system requires that the public share responsibility. Social Sciences in China, 27, Chinese Academy of Social Sciences (CASS), Beijing. 